\title{
Diurnal variations in integrated water vapor derived from a GPS ground network in the Volga-Ural region of Russia
}

\author{
Vladislav V. Kalinnikov and Olga G. Khutorova \\ Kazan (Volga Region) Federal University, Kremlevskaya Str. 18, 420008, Kazan, Russia \\ Correspondence to: Vladislav V. Kalinnikov (vlad-kalinnikov@mail.ru)
}

Received: 23 October 2016 - Revised: 2 March 2017 - Accepted: 3 March 2017 - Published: 21 March 2017

\begin{abstract}
In this article, we present estimates of diurnal and semidiurnal harmonics of variations in integrated water vapor content (IWV) according to data from 16 GPS stations in the Volga-Ural region of Russia during 2013-2015. Amplitudes of diurnal harmonics are maximal in summer and reach values from 0.37 to $1.01 \mathrm{~mm}$. Time at the maximum of diurnal harmonic is typically in the period from 14:00 to 17:00. Semidiurnal harmonics have the largest amplitudes in spring and autumn, but they do not exceed $0.19 \mathrm{~mm}$. A comparison of the diurnal cycle from GPS data and ERA-Interim reanalysis has revealed significant differences in the phase. It is established that, as a result of evaporation from the underlying surface and convective lifting of moist air, the summer diurnal variations in IWV and surface density of water vapor are in antiphase. The diurnal cycle of IWV is determined by surface air temperature to be $88 \%$ in summer and less than at $35 \%$ in other seasons. It is noted that maximal amplitudes of diurnal harmonic of IWV are observed at stations located on the windward side of mountains.
\end{abstract}

Keywords. Atmospheric composition and structure (troposphere composition and chemistry) - meteorology and atmospheric dynamics (climatology) - radio science (remote sensing)

\section{Introduction}

Atmospheric water vapor is a major greenhouse gas and plays a key role in the radiation balance, the hydrological cycle and thermal energy conversion. The indicator characterizing the content of this gas in the atmospheric column is integrated water vapor (IWV). This value has high spatial and temporal variability that is dependent on the local climatic and topographic conditions. Diurnal variations in atmospheric IWV are associated with the processes of wet convection, precipitation, surface evaporation, condensation and wind regime. It is important to take into account the field of meteorological parameters with high spatial and temporal resolution. This gives one the chance to correctly consider these measurements in radiation models and in models of climate and weather forecasting (Wulfmeyer et al., 2015; Benjamin et al., 2010). Traditional techniques of IWV sounding such as radiosondes and satellite and ground-based radiometric systems give very limited data for the understanding of these processes. Moreover, long time series of high-precision IWV data are necessary for climate change monitoring and calibration of other techniques (Roman et al., 2012). Therefore, in the last two decades, ground-based receivers of GPS signals have begun to be used as IWV sensors. With this technology it is possible to obtain continuous estimates of IWV in any weather and with a spatial resolution that depends only on the number of receivers in ground network. It is now established that assimilation of GPS IWV in numerical weather prediction models improves short-range forecasts of cloudiness and relative humidity at different vertical levels (Bennitt and Jupp, 2012; Smith et al., 2007). In addition, GPS IWV data are useful in situations with high convection for prediction of the development of atmospheric vortices and heavy rainfall (Li and Deng, 2013; Means, 2013; Moore et al., 2015). However, it is noted that weather prediction models are poor predictors of the diurnal course of IWV without GPS data (Radhakrishna et al., 2015).

Currently studies of diurnal variations in GPS IWV for different areas are known (Dai et al., 2002; Glowacki et al., 2006; Jin et al., 2008; Ortiz de Galisteo et al., 2011). However, for assessment of the global water vapor content, some regions are insufficiently studied, which is particularly the case for Russia. Even its European territory is poorly cap- 
tured by the regular observations due to the large area and administrative division of the monitoring stations. In particular, this applies to the Volga-Ural region, which is adjacent to the southwestern slopes of the Ural Mountains. This area lies approximately between the 51 and 57 parallels of northern latitude, and through it pass the middle reaches of the Volga, the largest European river. The relief has a flat character with absolute altitudes of $100-200 \mathrm{~m}$. The only exception is the Volga Plateau along the right bank of the Volga, with altitudes of up to $360 \mathrm{~m}$. Mean temperatures in the region vary from -17 to $-10^{\circ} \mathrm{C}$ in January and from +18 to $+23^{\circ} \mathrm{C}$ in July. The annual precipitation is about $300-500 \mathrm{~mm}$. At the same time, mean temperatures and precipitation are maximal in the southwest of the region and minimal in the northeast. In the winter period in the study area, southeast wind is dominant and brings dry continental air from the western spur of the Central Asian anticyclone. In summer, northern and western prevailing winds transport moist sea air to the region from the Azores High and Barents Sea anticyclone.

Due to the latitude dependence of the incoming solar radiation, different levels of hydration of the underlying surface and the influence of orography in the considered territory local diurnal variations in IWV are formed. In order to study these variations, we used measurements taken from 16 GPS stations in the Volga-Ural region for the period 2013-2015. Information about the location of these stations is summarized in Table 1. Two of these stations (ARTU, KZN2) are part of networks of the International GNSS Service (http: //www.igs.org). Six stations (DIMI, OREN, SAMR, SURA, TOLI, ULIA) are part of the fundamental astro-geodetic network of the Russian Federation. Seven stations (ALME, ATNI, CHEL, MENZ, NOVO, TYUL, ZAIN) are part of a regional geodetic network of high-precision real-time positioning. Finally, one station (UFAB) is in the scientific use of Bashkir State University.

\section{Basic theory}

For the processing of GPS signal measurements in the Kazan Federal University, a proprietary application, TropoGNSS, was developed using the strategy of precise point positioning (Kouba, 2015; Xu, 2007). The algorithm is based on a comparison of the length of the signal phase paths between satellites and the ground receiver, with geometric distances between them. Geometric distances are calculated taking into account changes in receiver antenna position due to the ocean loading effect as well as solid and pole tides (Petit and Luzum, 2010). The main contribution of the ionospheric layer to phase path is excluded by using measurements on two standard frequencies: 1575.42 and $1227.60 \mathrm{MHz}$. The small residual ionospheric effect usually does not exceed the first millimeter and is not considered (Bassiri and Hajj, 1993; Schaer, 1999). The slant delay of GPS signals in electrically neutral atmosphere is parameterized by multiplication

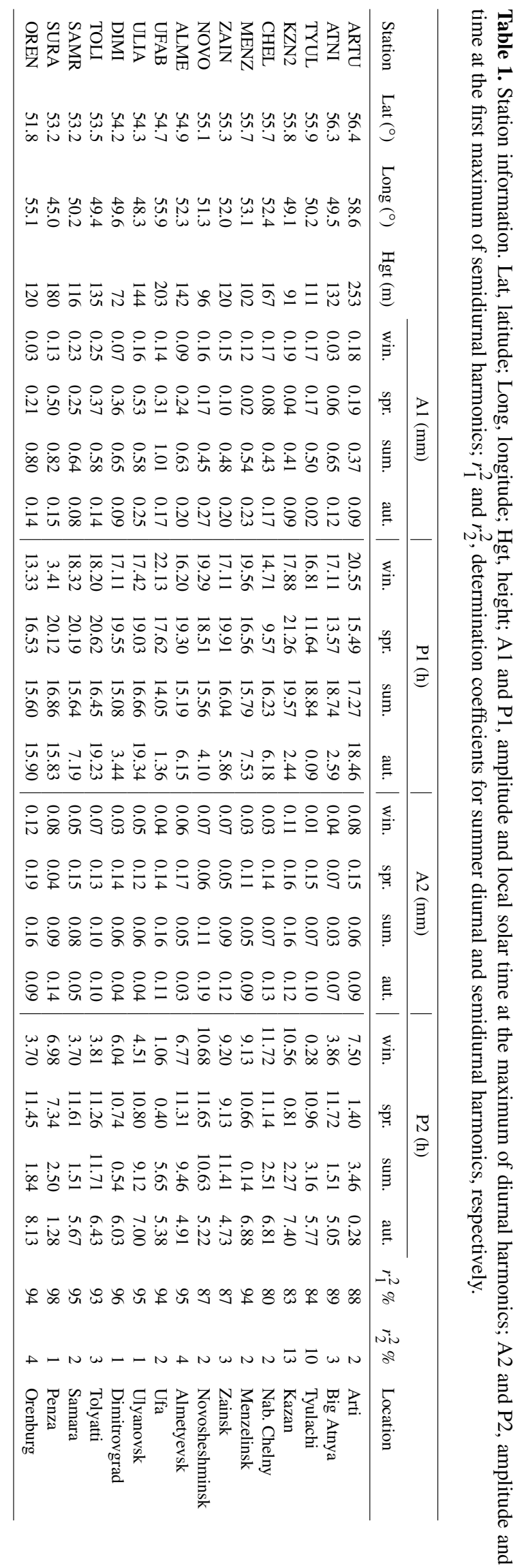

www.ann-geophys.net/35/453/2017/ 
of zenith tropospheric delay (ZTD), which is common for all synchronously observed satellites, and using Niell's mapping function. This is determined by the zenith angle of each satellite (Niell, 1996). The zenith cutoff angle in our processing is established at $83^{\circ}$. Time series of phase measurements are sequentially adjusted by a Kalman filter in which the unknowns are the phase ambiguities and ZTD. Ambiguities are not fixed further to the nearest integral number since they cannot be separated from instrumental delays of satellites in the precise point positioning mode (Ge et al., 2008). We get output ZTD series with a discretization of $5 \mathrm{~min}$.

The parameter ZTD is the integral from refraction index in the vertical direction (Mendes, 1999). As the three-term empirical formula of the refractive index is linear with respect to the total atmospheric pressure and the partial pressure of water vapor (Bevis et al., 1994), the ZTD value can be divided into hydrostatic (ZHD) and wet (ZWD) components:

$\mathrm{ZTD}=\mathrm{ZHD}+\mathrm{ZWD}$.

If surface pressure at the station is known, the hydrostatic component is determined with accuracy of about $1 \mathrm{~mm}$ using the Saastamoinen model (m) (Saastamoinen, 1972):

$\mathrm{ZHD}=\frac{10^{-6} \cdot K_{1} \cdot R_{\mathrm{d}} \cdot P_{\mathrm{S}}}{g_{0} \cdot(1-0.00266 \cdot \cos 2 B-0.00028 \cdot H)}$,

where $K_{1}\left(77.60 \mathrm{~K} \mathrm{hPa}^{-1}\right)$ is the first coefficient of threeterm refractive index formula; $R_{\mathrm{d}}\left(287 \mathrm{~J} \mathrm{~kg}^{-1} \mathrm{~K}^{-1}\right)$ is the specific gas constant of dry air; $P_{\mathrm{S}}$ is surface pressure at the station $(\mathrm{hPa}) ; g_{0}\left(9.784 \mathrm{~m} \mathrm{~s}^{-2}\right)$ is gravity in the mass center of atmospheric column on the Equator; and $B$ and $H$ is station latitude $\left(^{\circ}\right)$ and height $(\mathrm{km})$. By subtracting ZHD from ZTD, the ZWD value can be found. Furthermore, ZWD, expressed in millimeters, is transformed to integrated water vapor content IWV $(\mathrm{mm})$ using the following expression (Askne and Nordius, 1987):

$\mathrm{IWV}=\frac{\mathrm{ZWD} \times 10^{8}}{\rho_{\mathrm{W}} \cdot R_{\mathrm{W}} \cdot\left(K_{2}-K_{1} \cdot \frac{R_{\mathrm{d}}}{R_{\mathrm{W}}}+\frac{K_{3}}{T_{\mathrm{m}}}\right)}$,

where $\rho_{\mathrm{w}}\left(1000 \mathrm{~kg} \mathrm{~m}^{-3}\right)$ is liquid water density; $R_{\mathrm{W}}$ $\left(461.5 \mathrm{~J} \mathrm{~kg}^{-1} \mathrm{~K}^{-1}\right)$ is the specific gas constant of water vapor; $K_{2}\left(69.4 \mathrm{~K} \mathrm{hPa}^{-1}\right)$ and $K_{3}\left(370100 \mathrm{~K}^{2} \mathrm{hPa}^{-1}\right)$ are the second and third coefficients of the three-term refractive index formula; and $T_{\mathrm{m}}$ is the mean weighted temperature of atmospheric column $(\mathrm{K})$. The mean weighted temperature is the greatest ambiguity for conversion of ZTD to IWV. With an average accuracy of $3 \mathrm{~K}$, it can be estimated from the surface temperature $T_{\mathrm{S}}(\mathrm{K})$ using the global regression expression (Mendes, 1999):

$T_{\mathrm{m}}=50.4+0.789 \cdot T_{\mathrm{s}}$.

Note that the contribution of non-gaseous components in the ZTD value (such as aerosols and hydrometeors) is typically at the level of less than a few millimeters (Solheim et al., 1999). These effects are usually not modeled.
Table 2. GPS-radiosonde comparison.

\begin{tabular}{lrrr}
\hline Site & $\begin{array}{r}\text { GPS-radiosonde } \\
\text { dist. }(\mathrm{km})\end{array}$ & $\begin{array}{r}\text { GPS-radiosonde } \\
\text { mean dev. }(\mathrm{mm})\end{array}$ & $\begin{array}{r}\text { GPS-radiosonde } \\
\text { SD (mm) }\end{array}$ \\
\hline KZN2 & 7.8 & -0.9 & 2.0 \\
UFAB & 7.8 & -0.9 & 1.7 \\
SURA & 9.2 & -1.4 & 2.2 \\
SAMR & 61.0 & 1.1 & 2.4 \\
OREN & 7.6 & 0.9 & 2.2 \\
\hline
\end{tabular}

\section{Diurnal harmonic analysis}

High temporary discretization of integrated water vapor content obtained from GPS data allows for consideration of diurnal variations in this value. As was done in Dai et al. (2002), the diurnal variations were averaged for all years for each season. In the considered region four seasons are defined: winter (December, January, February), spring (March, April, May), summer (June, July, August) and autumn (September, October, November). Furthermore, we subject the mean diurnal variation to harmonic analysis:

$$
\begin{aligned}
\operatorname{IWV}(t) & =\operatorname{IWV}_{0}+\sum_{n=1}^{2} a_{n} \cdot \sin \left(2 \cdot \pi \cdot n \cdot \frac{t}{24}\right) \\
& +b_{n} \cdot \cos \left(2 \cdot \pi \cdot n \cdot \frac{t}{24}\right)+\varepsilon,
\end{aligned}
$$

where $n$ is harmonic number; $t$ is local solar time (LST) at the station; $\mathrm{IWV}_{0}$ is daily mean IWV (mm); $a_{n}$ and $b_{n}$ are the unknown coefficients of inner diurnal harmonics $(\mathrm{mm})$; and $\varepsilon$ represents other variations in IWV, associated with harmonics above the second order. For every season, amplitude $A_{n}=\left(a_{n}^{2}+b_{n}^{2}\right)^{1 / 2}$ and phase $\varphi_{n}=\arctan \left(b_{n} / a_{n}\right)$ of diurnal $(n=1)$ and semidiurnal $(n=2)$ harmonics are defined. Furthermore, we will present a phase in the form of time at the maximum $P_{n}=\left(\pi / 2-\varphi_{n}\right) \cdot 12 /(\pi \cdot n)$. For a semidiurnal component, time at the first maximum will be considered. As can be clearly seen in the values of the determination coefficients in Table 1, the diurnal harmonic covers more than $80 \%$ of the inner diurnal variations in summer period at all stations. In winter, the determination coefficients for diurnal and semidiurnal harmonics are equal to $35-72$ and 4-20\%, respectively. The exception is OREN station, where the determination coefficient of semidiurnal harmonics is equal to $65 \%$.

\section{Results}

\subsection{Comparison with radiosonde and ERA-Interim data}

To get an idea of the accuracy of individual GPS IWV samples and mean diurnal variations, it is necessary to carry out a 

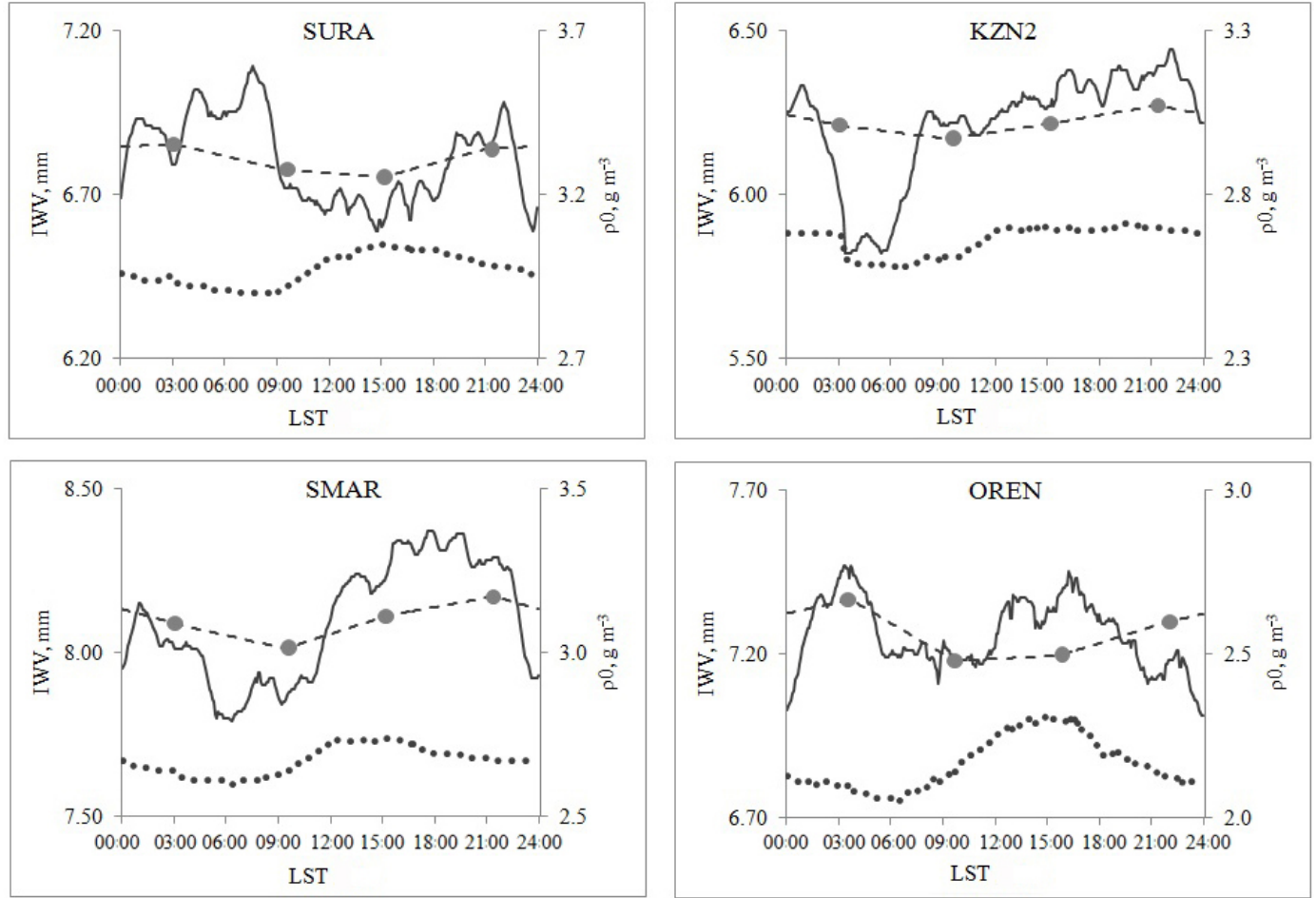

(a)
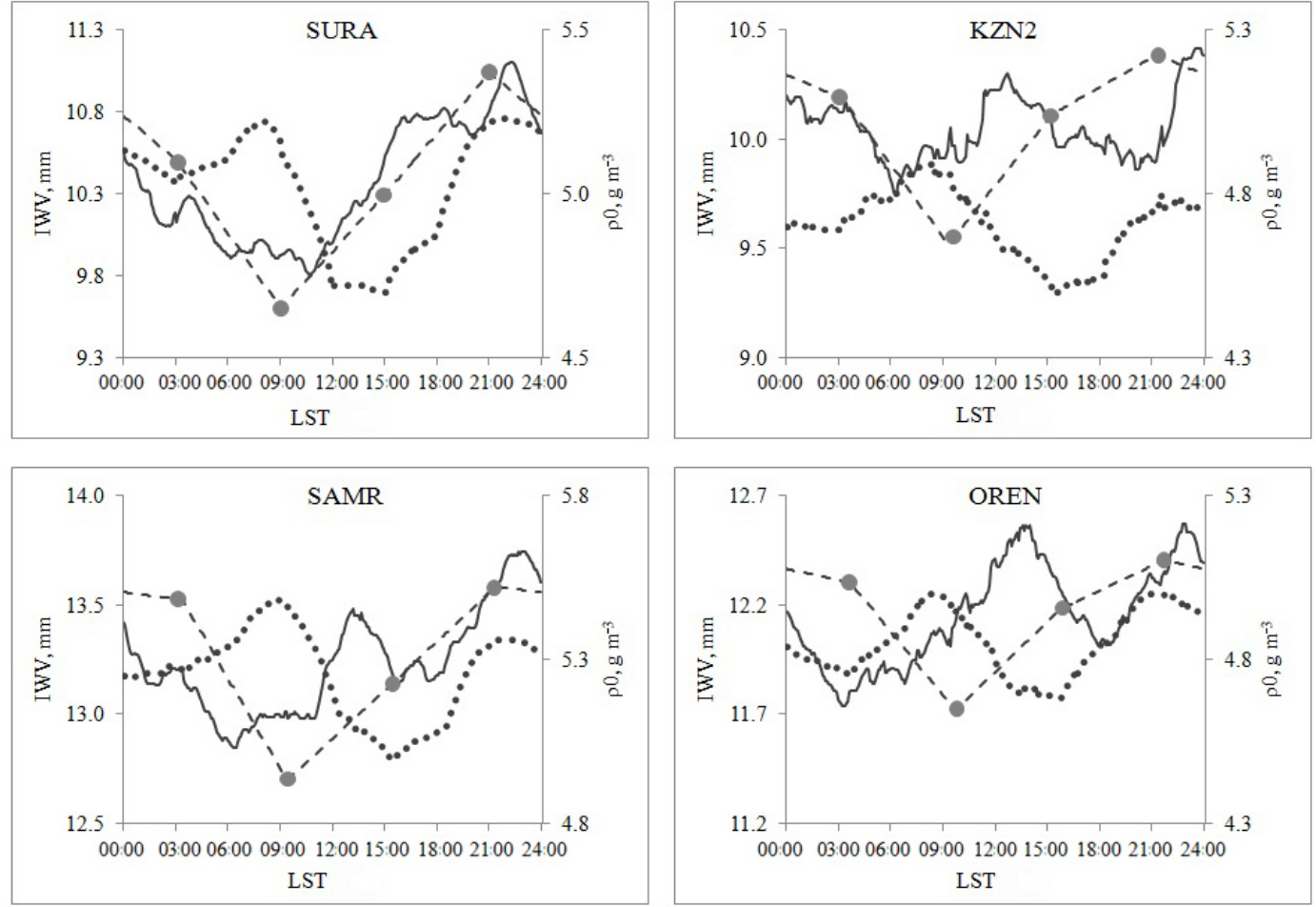

(b)

Figure 1. 

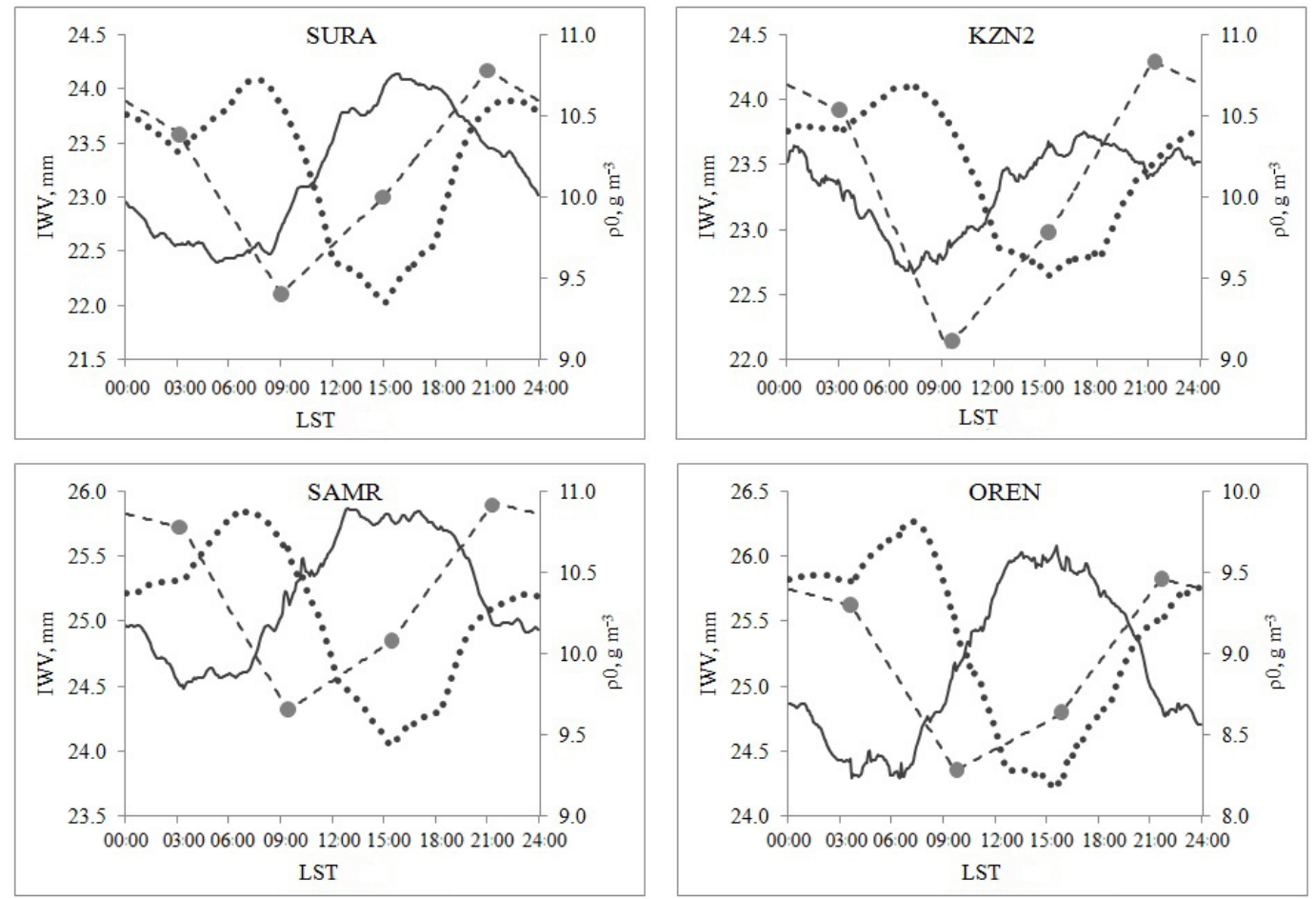

(c)
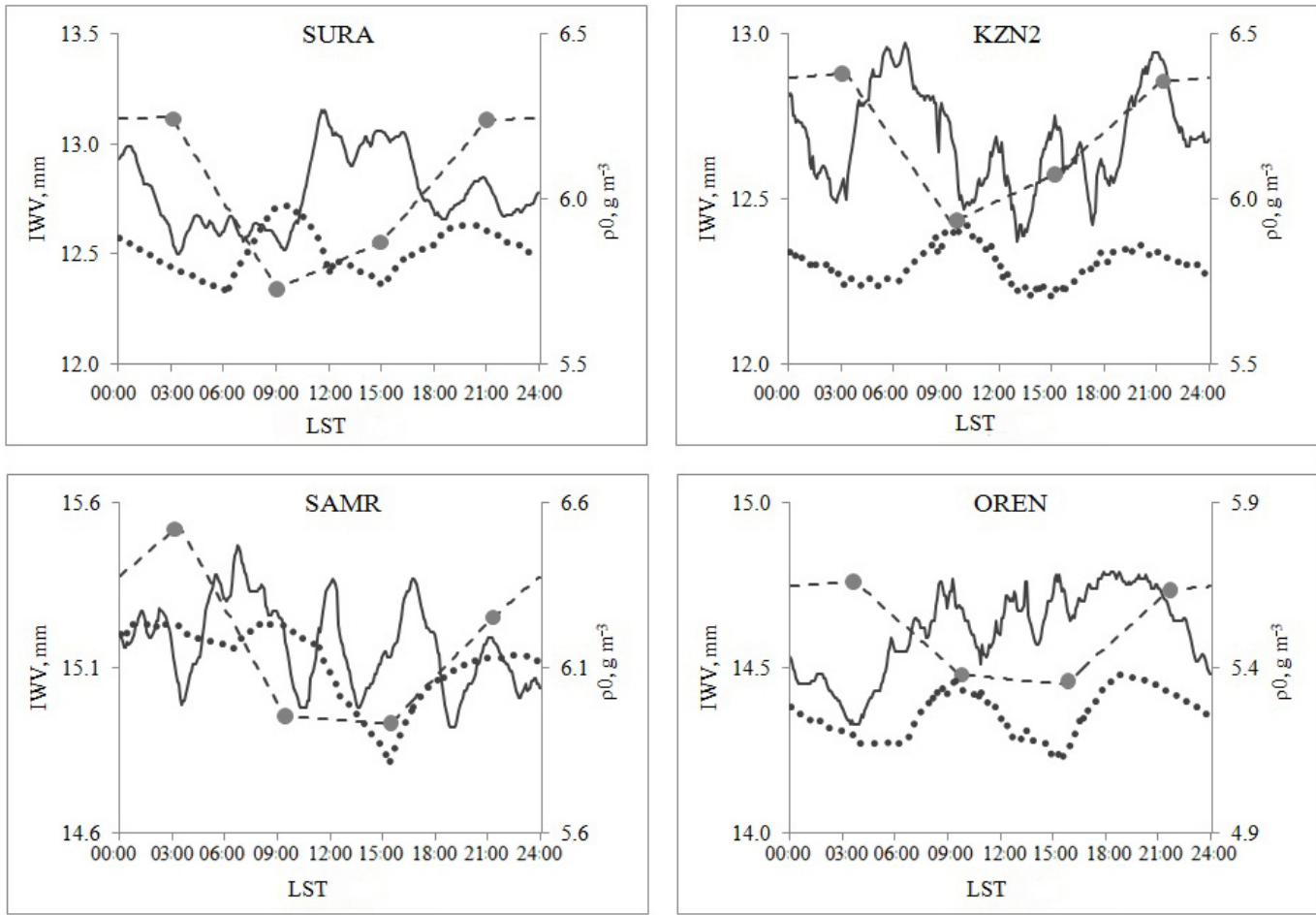

(d)

Figure 1. Mean diurnal variations in surface water vapor density $\rho_{0}$ (dotted curve), IWV from GPS (solid curve) and ERA-Interim (dashed curve) data at four GPS stations for winter (a), spring (b), summer (c) and autumn (d). 
comparison with independent data. For this purpose we carried out verification of IWV time series of GPS stations with the help of the same values calculated on vertical profiles of pressure, temperature and relative humidity at the nearest radiosonde launch sites. The results are presented in Table 2. It should be noted that the reasons for nonzero mean deviations are overestimations of the hydrostatic component of tropospheric delay by the Saastamoinen model due to disturbance of the hydrostatic equilibrium and ambiguity of refraction coefficient $K_{1}$ (Brenot et al., 2006; Rueger, 2002). On the other hand, the radiosonde can overestimate IWV in cloudy weather because of moisture condensing on humidity sensor contacts (Guerova et al., 2003). The standard deviation for all stations is about $2.0 \mathrm{~mm}$. This is an average value obtained by comparing radiosonde and GPS estimates of integrated water vapor. Globally, the standard deviation in GPS-radiosonde pairs varies from about 0.5 to $5 \mathrm{~mm}$ and tends to increase from poles to the Equator (Glowacki et al., 2006; Birkenheuer and Gutman, 2005; Haas et al., 2011; Pacione et al., 2002; Raju et al., 2005). All time series of IWV are in good agreement and have a coefficient of correlation of 0.96-0.98. The standard deviation of IWV samples in mean diurnal variations depends on the number of averaging days. For the 3 -year period, about 270 days fall on every season. This gives an approximate standard deviation of $2.0 \mathrm{~mm} / \sqrt{ } 270 \approx 0.12 \mathrm{~mm}$ for the mean IWV sample, and the $2 \sigma$ confidence level is $0.24 \mathrm{~mm}$. In practice, GPS data gaps increase the standard deviation of mean IWV samples to $0.18 \mathrm{~mm}$.

Unfortunately, radiosonde launches are made only once every $12 \mathrm{~h}$, which does not allow for diurnal variations to be traced. Therefore, it is interesting to compare mean diurnal variations in IWV for the same years from GPS data and 6hourly ERA-Interim reanalysis (Dee et al., 2011). Figure 1 shows a comparison for four stations. It is clearly seen that diurnal variations in IWV from reanalysis data are smoother and do not display local effects. This can be explained by the integrated forecasting system of ERA-Interim with a $12 \mathrm{~h}$ analysis window and spatial resolution of $80 \mathrm{~km}$. For example, reanalysis does not allow for local peaks to be seen in 12:00-18:00 on autumn graphs. In summer, diurnal variations in IWV are best expressed and reanalysis shows approximately correct amplitudes of variations, but there are offsets in phase of about 4-5 h. According to Jakobson et al. (2014), differences in diurnal amplitudes of IWV between GPS and reanalysis can be explained partly by insufficient averaging over the interval of several years. However, it cannot explain differences in phases, especially in summer. It is likely that reanalysis insufficiently takes local climatic factors into account, and it proves the usefulness of assimilation of GPS data in weather forecasting models (Guerova et al., 2016).

\subsection{Diurnal and semidiurnal variations}

Figure 1 and Table 1 show amplitudes and time at the maximums of diurnal harmonics. First of all we note that the values of the amplitudes are rather small relative to the IWV magnitude: seasonal mean IWV on stations are $4.8-8.1 \mathrm{~mm}$ in winter, $9.3-13.2 \mathrm{~mm}$ in spring, $22.2-25.2 \mathrm{~mm}$ in summer and $11.5-15.2 \mathrm{~mm}$ in autumn. Figure 2 clearly shows that the maximum of amplitudes is observed in summer and the minimum in winter. Diurnal amplitudes more than $0.5 \mathrm{~mm}$ are found only in summer and spring. In the latter case they appear only at stations in the southwest of the considered region and this station shows maximal relative amplitudes (4-5\% of seasonal mean). In spring and autumn, relatively large amplitudes (more than $0.2 \mathrm{~mm}$ ) are observed at the stations in the southern half of the region. This area is narrowed to two stations on the Volga (SAMR, TOLI) during the winter period.

Regarding the time at the maximum, it is possible to note that the minimum of geographical dispersion of this parameter occurs in summer, when the diurnal harmonic stands out most clearly. In spring, in the southern part of the region, the maximum occurs in the evening (from 18:30 to 20:40). The maximum comes in the second half of day (from 15:30 to 17:40) in the Ural area and around noon in the north of the region. The zone with the maximum in the second half of day (from 14:10 to 17:20) extends to most stations in summer. The exception is the northwest stations, where the maximum occurs in the evening (about 19:00). In autumn the field of spatial distribution of time at the maximum is strongly noisy, and in winter in general the situation is opposite to summer: time of the maximum is in the second half of day for the northwestern zone and in the evening in the more southern zone.

Figure 3 shows amplitudes and time at the first maximums for semidiurnal harmonics. In general, semidiurnal amplitudes are weaker than diurnal ones and do not exceed $0.19 \mathrm{~mm}$ ( $2 \%$ of seasonal mean). Nevertheless, in transitional spring and autumn periods, semidiurnal amplitudes are maximal and exceed diurnal ones for some stations. Thus, in spring, for example, at the station MENZ diurnal amplitude is $0.02 \mathrm{~mm}$, whereas semidiurnal amplitude reaches $0.11 \mathrm{~mm}$.

The time of the first maximum of semidiurnal harmonic is usually around noon in spring and in the early morning in autumn. In winter and in summer the field of this parameter is strongly noisy.

\section{Discussion}

It was noted above that the diurnal variations in integrated water vapor content is caused by the convective motion of moist air, evaporation from the underlying surface, condensation, and precipitation and wind circulation as well as orography of surrounding areas. The first two factors are directly 

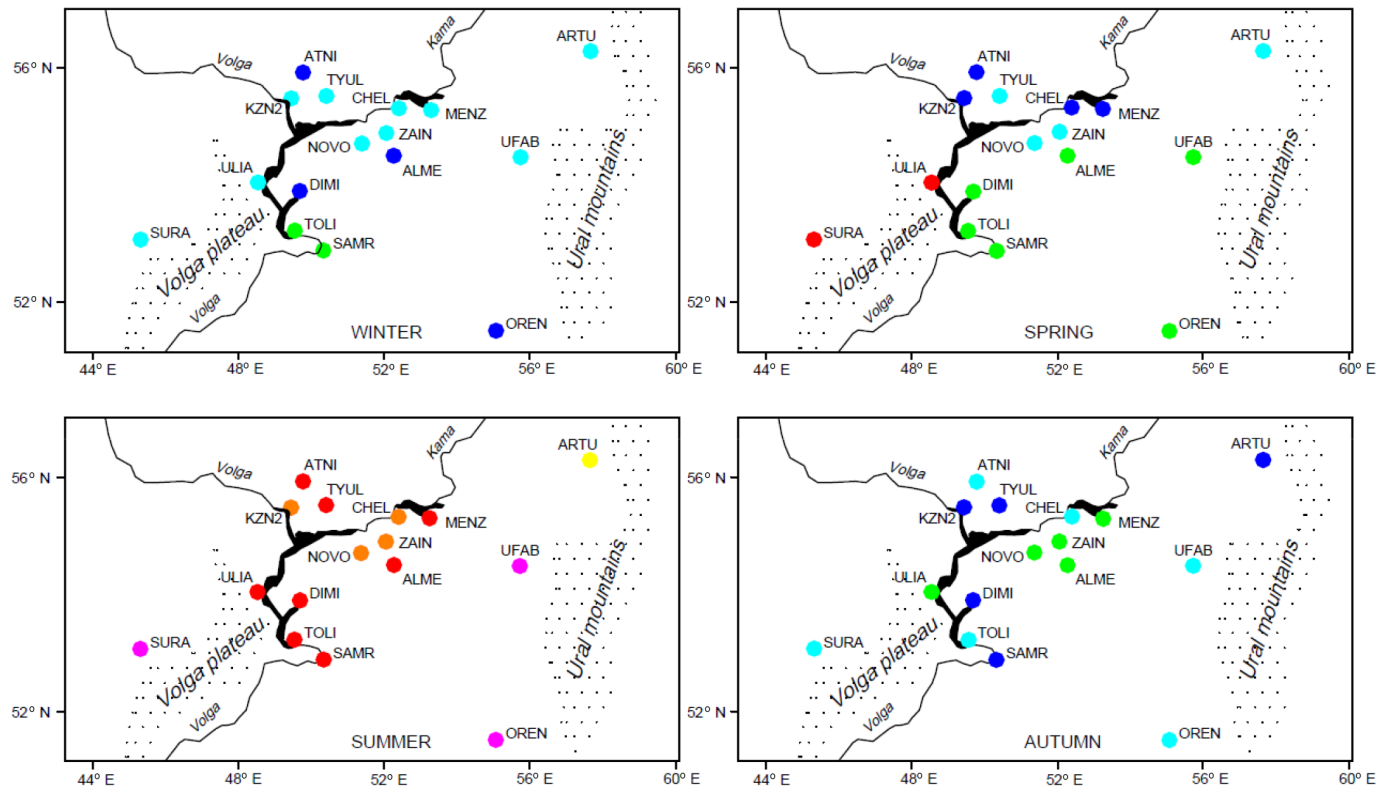

(a)
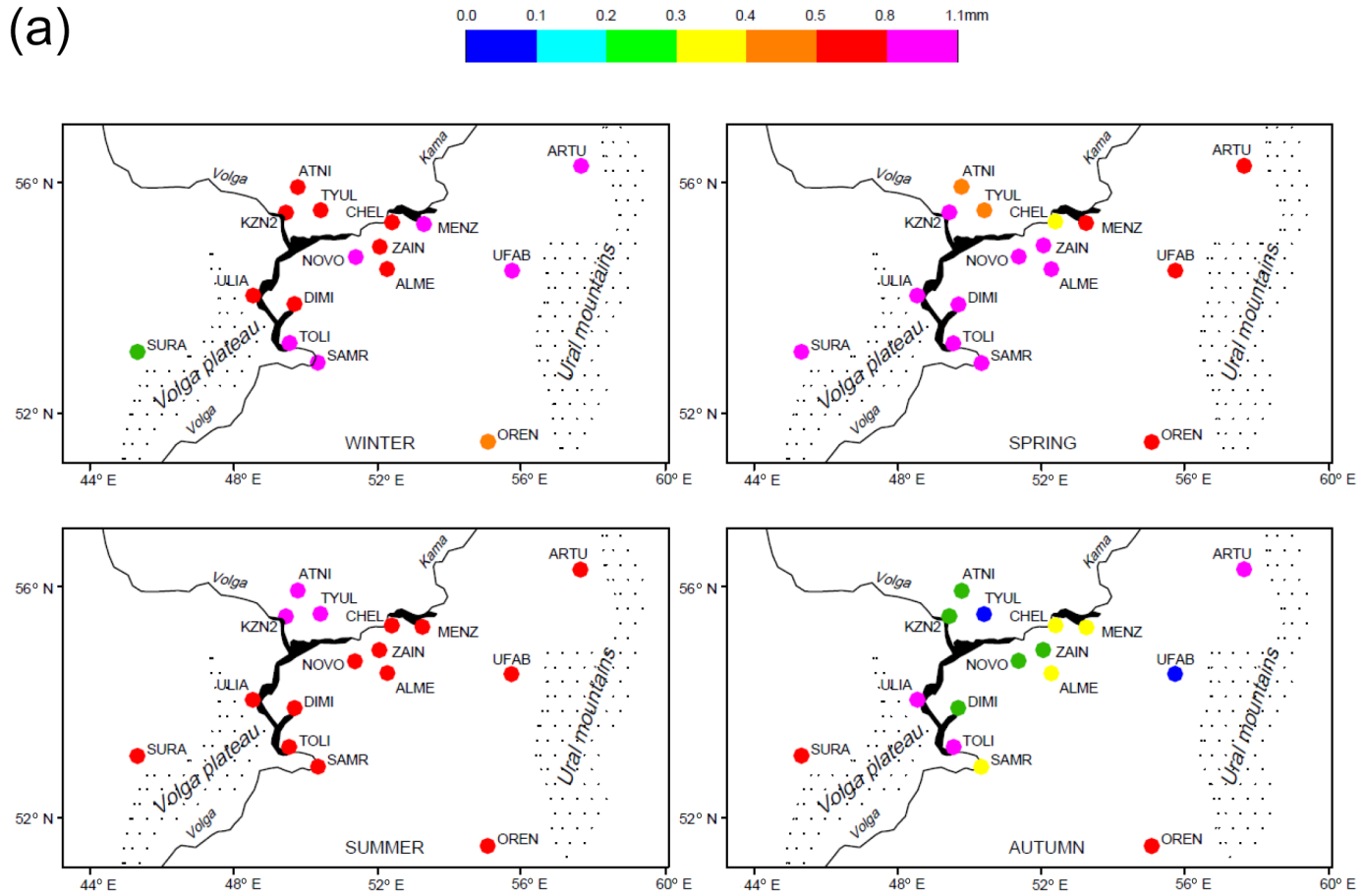

(b)

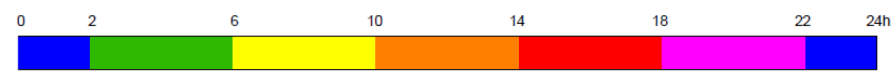

Figure 2. Amplitude (a) and time at the maximum (b) of diurnal harmonic. 

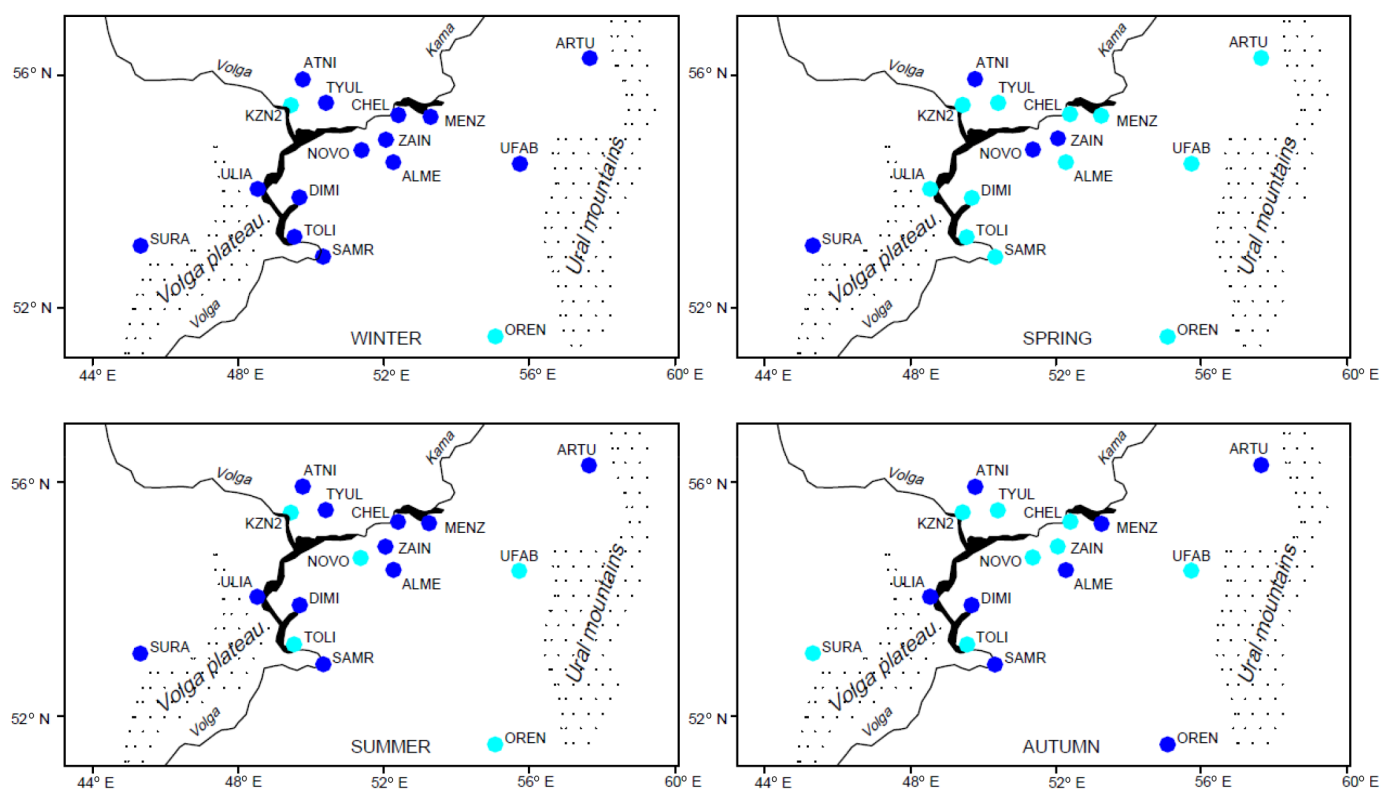

(a)
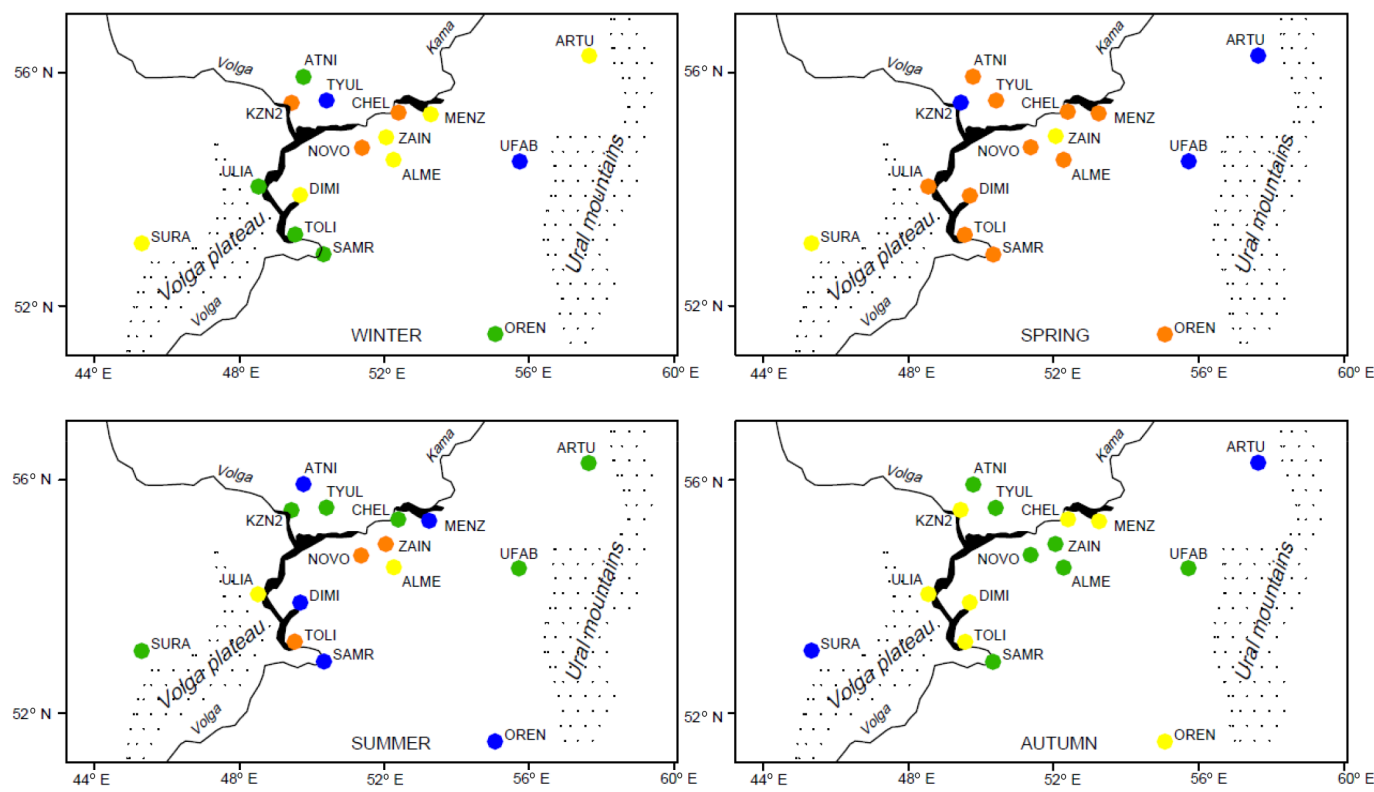

(b)

Figure 3. Amplitude (a) and time at the first maximum (b) of the semidiurnal harmonic. 

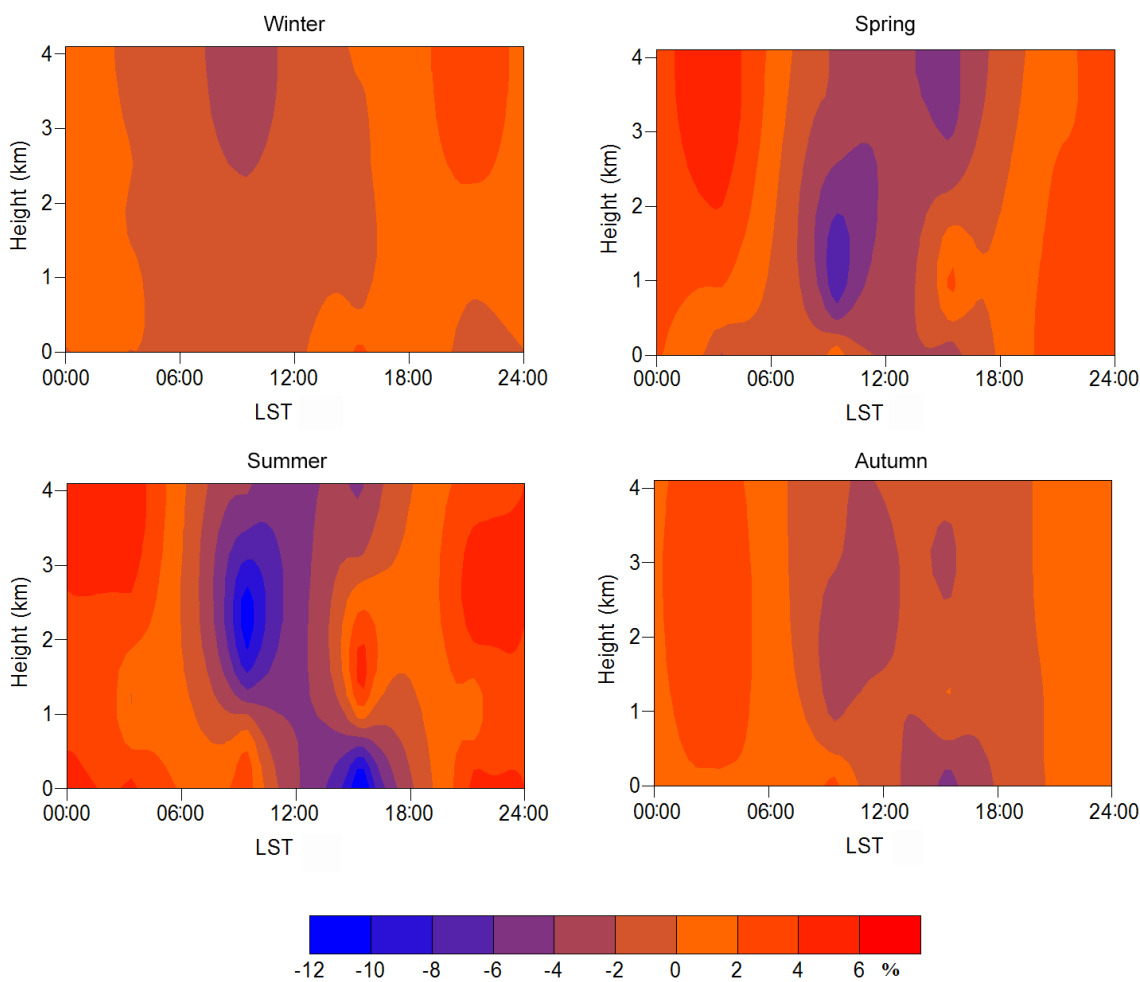

Figure 4. Mean diurnal anomalies of water vapor density (percentage of daily mean at each level) for SAMR station according to ERAInterim reanalysis data in the period 2013-2015.

controlled by the influx of solar radiation and are dominant in conditions of remoteness of the Volga-Ural region from coastlines of the Eurasian continent. Convective motions and evaporations are interconnected with the thermal regime. In summer, the mean for all regional stations' diurnal course of IWV (not shown) is well determined by surface temperature (determination coefficient is more than $88 \%$ ). Diurnal course is less expressed in other seasons, and determination coefficients with temperature are $35 \%$ in winter, $31 \%$ in spring and $1 \%$ in autumn. Diurnal course is strongly disturbed in autumn by series of local peaks, one of which coincides with the maximum of temperature. Other peaks are probably related to diurnal variations in precipitation. It is also noted that the higher the diurnal amplitude of temperature at a station, the higher the diurnal amplitude of IWV.

Figure 1 shows examples of mean diurnal variations in IWV in comparison with the same variations for surface density of vapor for four stations. As is well visible for summer graphs, fluctuations in both variables are in antiphase: IWV maximum at about 15:00 corresponds to a minimum of vapor density; IWV minimum at about 07:00 corresponds to a maximum of vapor density. The observed effect is well described by convective motions. Thus, water vapor falls to the underlying surface and condenses after a rather cold night. Consequently, it causes IWV decrease, but an increase in water vapor density is observed at the surface as a result of contin- uous inflow of water vapor from upper layers. After sunrise, the underlying surface begins to warm up and the process of water vapor lifting begins again. Since the rate of evaporation from the surface is less than lifting speed, the evaporation does not manage to fill the amount of water vapor which rose to the upper layers. Therefore, IWV increases, whereas water vapor density decreases at the surface. Diurnal variations in wind speed also play a role in increasing water vapor. They are controlled by air temperature and cause turbulent mixing in the boundary layer (Matveev, 1967). Therefore, it is interesting to consider the vertical structure of diurnal variations in water vapor according to ERA-Interim reanalysis. Figure 4 shows mean anomalies of water vapor density as a percentage of daily mean at SAMR station for the period 2013-2015 at heights from 0 to $4 \mathrm{~km}$. However, as was specified in Sect. 4.1, reanalysis has offsets in phase of diurnal variations; nevertheless, certain regularities are clearly visible. For example, in summer and spring, the diurnal cycle of water vapor has specific positive anomalies at heights of 1$3 \mathrm{~km}$ at about 15:00, which is very similar to results of Dai et al. (2002). In the afternoon during all seasons, a minimum of anomalies in all layers is observed.

It is necessary to note the role of wind regime. The VolgaUral region is an inland area and removed from the main sources of water vapor in the atmosphere (such as seas and oceans). Therefore, seasonal values of IWV are largely deter- 
mined by synoptic regularities in the distribution of the wind field. During warm times, moist tropical air masses actively penetrate into the region from the Mediterranean Sea and Azores High (Perevedentsev et al., 2010). On their way in the northeast direction, moist air masses produce rainfall and reduce their own water vapor content. As a result, rather stable southwest horizontal gradients of IWV are observed in the region (Kalinnikov et al., 2013). Rather high spring amplitudes in SURA and ULIA are probably partly bound to these gradients. In the cold period the Volga-Ural region is within the western spur of the Central Asian anticyclone thanks to the dry continental air masses that are formed here. Inaccessibility of the region for warm western currents causes minimum diurnal amplitudes of IWV that are less than ones in the more northern Baltic area (Jakobson et al., 2009).

The effect of local wind circulation on diurnal variations in IWV is usually large enough for coastal stations. In these cases there is clear diurnal variation in breeze direction that transports moist sea air to surrounding areas of continents (Bastin et al., 2007; Ortiz de Galisteo et al., 2011). In the Volga-Ural region there is only one large water mirror the breeze effect is observed - the Kuybyshev Reservoir in the lower reaches of the Kama River, having a width of up to $36 \mathrm{~km}$. However, none of the considered stations is on its banks. Therefore, the contribution of local wind circulation in the diurnal cycle of IWV is defined only by turbulent raising of water vapor as noted above.

Separately, the influence of orography should be noted. It is well known that mountain systems significantly influence local circulation of the atmosphere. Air masses encounter high areas and seek to flow over them, which leads to emergence of upflow, development of clouds and an increased quantity of precipitation on the windward side (Egger and Hoinka, 1992; Hoinka and Volkert, 1992; Blumen, 1992; Keuler et al., 1992; Houze Jr., 2012). Thus, even small hills in conditions of quasi-flat topography influence the nonuniform structure of meteorological fields (Zinin et al., 2006). It is experimentally established that local orography promotes generation of quasi-periodic mesoscale disturbances (Khoutorova and Teptin, 2009). It is also noted that diurnal amplitudes of IWV have increased values for mountainous and foothill areas (Li et al., 2008; Jin et al., 2008). In the Volga-Ural region there are two well-marked mountain chains stretching from north to south and blocking path of the western cyclones: the Volga Plateau (altitudes up to $360 \mathrm{~m}$ ) and the Ural Mountains (altitudes up to $1500 \mathrm{~m}$ in the southern part). In our research the largest summer amplitudes are found at stations SURA (on the windward side of the Volga Uplands), UFAB and OREN (on the windward side of the Ural Mountains). ARTU is also located on the windward side of the Ural Mountains but does not show rather large amplitude, which is probably associated with the extreme northeast position in the considered region and the influence of the southwest horizontal gradient of IWV.

\section{Conclusions}

The article describes diurnal and semidiurnal variations in integrated water vapor content (IWV) according to data from 16 GPS stations in the Volga-Ural region of Russia in the period 2013-2015. Preliminary comparison of time series of GPS IWV with independent radiosonde measurements showed mutual agreement at the level of $2 \mathrm{~mm}$. Comparison of the diurnal cycle from GPS data and ERA-Interim reanalysis has revealed significant differences in the phase. Thus, it is confirmed that weather prediction models poorly predict the diurnal course of IWV and, according to previous studies, assimilation of GPS data would likely be useful for improving regional analysis and weather forecasting. Regarding diurnal harmonics, it is established that amplitudes reach values from 0.37 to $1.01 \mathrm{~mm}$ in summer and from 0.03 to $0.25 \mathrm{~mm}$ in winter. Time at the maximum of diurnal harmonic winter and summer falls within the period from 14:00 to 17:00 for most stations. Semidiurnal harmonics show rather small amplitudes which do not exceed $0.19 \mathrm{~mm}$. At the same time they are maximal in spring and autumn and are minimal in summer and winter. The time of the first maximum of semidiurnal harmonic is around noon in spring and in the early morning in autumn. The diurnal cycle of IWV is determined by surface air temperature at $88 \%$ in summer and less than $35 \%$ in other seasons. It is shown that summer diurnal variation in the surface density of water vapor is in antiphase with diurnal variation in IWV, which is bound to evaporation and convective motions of moist air. According to ERA-Interim reanalysis, the rising moist air produces a positive evening anomaly of water vapor density at heights of $1-3 \mathrm{~km}$ during the summer. It is also found that the largest summer amplitudes of IWV are observed at stations located on the windward side of mountains.

Data availability. Data from ARTI and KZN2 stations are freely available from ftp servers of IGS Analytic Centers (for example, CDDIS, ftp://cddis.gsfc.nasa.gov/gps/data/daily). Data from other stations are available by agreement with the owner organizations.

Competing interests. The authors declare that they have no conflict of interest.

Acknowledgements. The work is performed according to the Russian Government Program of Competitive Growth of Kazan Federal University. The authors express their gratitude to the Middle Volga Aero Geodetic Enterprise of Roskartografiya, the Ministry of Information and Communication of the Republic of Tatarstan, and Bashkir State University for the possibility to use data of the ground GPS station network.

The topical editor, M. Salzmann, thanks J. P. Ortiz-de-Galisteo and one anonymous referee for help in evaluating this paper. 


\section{References}

Askne, J. and Nordius, H.: Estimation of tropospheric delay for microwaves from surface weather data, Radio Sci., 22, 379-386, 1987.

Bassiri, S. and Hajj, G. A.: Higher-order ionospheric effects on the global positioning system observables and means of modeling them, Manuscr. Geodaet., 18, 280-289, 1993.

Bastin, S., Champollion, C., Block, O., Drobinski, P., and Masson, F.: Diurnal cycle of water vapor as documented by a Dense GPS Network in a coastal area during ESCOMPTE IOP2, J. Appl. Meteorol. Clim., 46, 167-182, 2007.

Benjamin, S. G., Jamison, B. D., Moninger, W. R., Sahm, S. R., Schwartz, B. E., and Schlatter, T. W.: Relative short-range forecast impact from aircraft, profiler, radiosonde, VAD, GPS-PW, METAR, and Mesonet observations via the RUC hourly assimilation cycle, Mon. Weather Rev., 138, 1319-1343, 2010.

Bennitt, G. and Jupp, A.: Operational assimilation of GPS zenith total delay observations into the met office numerical weather prediction model, Mon. Weather Rev., 140, 2706-2719, 2012.

Bevis, M., Businger, S., Chiswell, S., Herring, T. A., Anthes, R. A., Rocken, C., and Ware, R. H.: GPS meteorology: mapping zenith wet delays onto precipitable water, J. Appl. Meteorol., 33, 379386, 1994.

Blumen, W.: Propagation of fronts and frontogenesis versus frontolysis over orography, Meteorol. Atmos. Phys., 48, 37-50, 1992.

Brenot, H., Ducrocq, V., Walpersdorf, A., Champollion, C., and Caumont, O.: GPS zenith delay sensitivity evaluated from highresolution numerical weather prediction simulations of the 8-9 September 2002 flash flood over southeastern France, J. Geophys. Res.-Atmos., 111, D15105, doi:10.1029/2004JD005726, 2006.

Dai, A., Wang, J., Ware, R. H., and Van Hove, T.: Diurnal variation in water vapor over North America and its implications for sampling errors in radiosonde humidity, J. Geophys. Res.-Atmos., 107, ACL 11-1-ACL 11-14, doi:10.1029/2001JD000642, 2002.

Dee, D. P., Uppala, S. M., Simmons, A. J., Berrisford, P., Poli, P., Kobayashi, S., Andrae, U., Balmaseda, M. A., Balsamo, G., Bauer, P., Bechtold, P., Beljaars, A. C. M., van de Berg, L., Bidlot, J., Bormann, N., Delsol, C., Dragani, R., Fuentes, M., Geer, A. J., Haimberger, L., Healy, S. B., Hersbach, H., Holm, E. V., Isaksen, L., Kållberg, P., Köhler, M., Matricardi, M., McNally, A. P., Monge-Sanz, B. M., Morcrette, J.-J., Park, B.-K., Peubey, C., de Rosnay, P., Tavolato, C., Thepaut, J.-N., and Vitart, F.: The ERA-Interim reanalysis: configuration and performance of the data assimilation system, Q. J. Roy. Meteor. Soc., 137, 553-597, 2011.

Egger, J. and Hoinka, K. P.: Fronts and Orography, Meteorol. Atmos. Phys., 48, 3-36, 1992.

Ge, M., Gendt, G., Rothacher, M., Shi, C., and Liu, J.: Resolution of GPS carrier-phase ambiguities in Precise Point Positioning (PPP) with daily observations, J. Geodesy, 82, 389-399, doi:10.1007/s00190-007-0187-4, 2008.

Glowacki, J., Penna, N. T., and Bourke, W. P.: Validation of GPSbased estimates of integrated water vapour for the Australian region and identification of diurnal variability, Aust. Meteorol. Mag., 55, 131-148, 2006.
Guerova, G., Brockmann, E., Quiby, J., Schubiger, F., and Matzler, C.: Validation of NWP mesoscale models with Swiss GPS network AGNES, J. Appl. Meteorol. Clim., 42, 141-150, 2003.

Guerova, G., Jones, J., Douša, J., Dick, G., de Haan, S., Pottiaux, E., Bock, O., Pacione, R., Elgered, G., Vedel, H., and Bender, M.: Review of the state of the art and future prospects of the groundbased GNSS meteorology in Europe, Atmos. Meas. Tech., 9, 5385-5406, doi:10.5194/amt-9-5385-2016, 2016.

Birkenheuer, D. and Gutman, S.: A comparison of GOES moisturederived product and GPS-IPW data during IHOP-2002, J. Atmos. Ocean. Tech., 22, 1838-1845, 2005.

Haas, R., Ning, T., and Elgered, G.: Long-term trends in the amount of atmospheric water vapour derived from space geodetic and remote sensing techniques, in: Proceedings of 3rd International Colloquium on Scientific and Fundamental Aspects of the Galileo Programme/ESA Proceedings WPP 326, Copenhagen, Denmark, 2011.

Hoinka, K. P. and Volkert, H.: Fronts and the Alps: Findings from the front experiment 1987, Meteorol. Atmos. Phys., 48, 51-75, 1992.

Houze Jr., R. A.: Orographic effects on precipitating clouds, Rev Geophys., 50, RG1001, doi:10.1029/2011RG000365, 2012.

Jakobson, E., Ohvril, H., and Elgered, G.: Diurnal variability of precipitable water in the Baltic region, impact on the transmittance of the direct solar radiation, Boreal Environ. Res., 14, 45-55, 2009.

Jakobson, E., Keernik, H., Luhamaa, A., and Ohvril, H.: Diurnal variability of water vapour in the Baltic Sea region according to NCEP-CFSR and BaltAn65+ reanalyses, Oceanologia, 56, 191204, 2014.

Jin, S., Li, Z., and Choa, J.: Integrated water vapor field and multiscale variations over China from GPS measurements, J. Appl. Meteorol. Clim., 47, 3008-3015, 2008.

Kalinnikov, V. V., Khutorova, O. G., and Teptin, G. M.: Influence nonuniformity of the atmospheric water vapor field on the phase measurements of radio signals from global navigation satellite systems, Izv. Vuz. Radiofiz+, 56, 96-103, 2013.

Keuler, K., Kerkmann, J., Kraus, H., and Schaller, E.: Orographical modification and large scale forcing of a cold front, Meteorol. Atmos. Phys., 48, 105-130, 1992.

Khoutorova, O. G. and Teptin, G. M.: An investigation of mesoscale wave processes in the surface layer using synchronous measurements of atmospheric parameters and admixtures, Izv. Atmos. Ocean. Phy+, 45, 549-556, 2009.

Kouba, J.: A guide to using international GNSS service (IGS) products, available at: http://kb.igs.org/hc/en-us/article_attachments/ 203088448/UsingIGSProductsVer21_cor.pdf (last access: 20 March 2017), 2015.

Li, G. and Deng, J.: Atmospheric water monitoring by using ground-based GPS during heavy rains produced by TPV and SWV, Adv. Meteorol., 2013, 793957, doi:10.1155/2013/793957, 2013.

Li, G., Kimura, F., Sato, T., and Huang, D.: A composite analysis of diurnal cycle of GPS precipitable water vapor in central Japan during Calm Summer Days, Theor. Appl. Climatol., 92, 15-29, 2008.

Matveev, L. T.: Fundamentals of general meteorology: physics of the atmosphere, Program for Scientific Translations, Jerusalem, Israel, 1967. 
Means, J.: GPS precipitable water as a diagnostic of the North American monsoon in California and Nevada, J. Climate, 26, 1432-1444, 2013.

Mendes, V. B.: Modeling the neutral-atmospheric propagation delay in radiometric space techniques, UNB, New Brunswick, Canada, Tech. Report 199, 1999.

Moore, A., Small, I., Gutman, S., Bock, Y., Dumas, J., Fang, P., Haase, J., Jackson, M., and Laber, J.: National weather service forecasters use GPS precipitable water vapor for enhanced situational awareness during the southern California summer monsoon, B. Am. Meteorol. Soc., 96, 1867-1877, 2015.

Niell, A. E.: Global mapping functions for the atmosphere delay at radio wavelengths, J. Geophys. Res.-Sol. Ea., 101, 3227-3246, 1996.

Ortiz de Galisteo, J. P., Cachorro, V., Toledano, C., Torres, B., Laulainen, N., Bennouna, Y., and de Frutos, A.: Diurnal cycle of precipitable water vapor over Spain, Q. J. Roy. Meteor. Soc., 137, 948-958, 2011.

Pacione, R., Fionda, E., Ferrara, R., Lanotte, R., Sciarretta, C., and Vespe, F.: Comparison of atmospheric parameters derived from GPS, VLBI and a ground-based microwave radiometer in Italy, Phys. Chem. Earth, 27, 309-316, 2002.

Perevedentsev, Y., Shantalinsky, K., and Tudry, V.: The global climate of the middle volga region, International Conference Global And Regional Climate Changes, Kyiv, Ukraine, 32-33, 2010.

Petit, G. and Luzum, B.: IERS Conventions, Bundesamt für Kartographie und Geodäsie, Frankfurt am Main, Germany, 2010.

Radhakrishna, B., Fabry, F., Braun, J., and Hove, T.: Precipitable water from GPS over the continental United States: Diurnal cycle, intercomparisons with NARR, and link with convective initiation, J. Climate, 28, 2584-2599, 2015.

Raju, S., Saha, K., Bijoy, V. T., and Parameswaran, K.: Measurement of integrated water vapor over Bangalore using ground based GPS data, in: Proceedings of URSI General Assembly, New Delhi, India, 23-29 October 2005.

Roman, J., Knuteson, R., Ackerman, S., Tobin, D., and Revercomb, H.: Assessment of regional global climate model water vapor bias and trends using precipitable water vapor (PWV) observations from a network of global positioning satellite (GPS) receivers in the U.S. great plains and Midwest, J. Climate, 25, 5471-5493, 2012.
Rueger, J. M.: Refractive indices of light, infrared and radio waves in the atmosphere, UNSW, Sydney, Australia, UNISURV Report S-68, 2002.

Saastamoinen, J.: Contributions to then theory atmospheric refraction. Part II. Refraction corrections in satellite Geodesy, B. Geod., 107, 13-34, 1973.

Schaer, S.: Mapping and predicting Earth's ionosphere using the Global Positioning System, PhD dissertation, Astronomical Institute, University of Berne, Switzerland, 1999.

Smith, T. L., Benjamin, S. G., Gutman, S. I., and Sahm, S.: Shortrange forecast impact from assimilation of GPS-IPW observations into the Rapid Update Cycle, Mon. Weather Rev., 135, 2914-2930, 2007.

Solheim, F. S., Vivekanandan, J., Ware, R. H., and Rocken, C.: Propagation delays induced in GPS signals by dry air, water vapor, hydrometeors, and other particulates, J. Geophys. Res.Atmos., 104, 9663-9670, 1999.

Wulfmeyer, V., Hardesty, R. M., Turner, D. D., Behrendt, A., Cadeddu, M. P., Di Girolamo, P., Schlüssel, P., Van Baelen, J., and Zus, F.: A review of the remote sensing of lower tropospheric thermodynamic profiles and its indispensable role for the understanding and the simulation of water and energy cycles, Rev. Geophys., 53, 819-895, doi:10.1002/2014RG000476, 2015.

$\mathrm{Xu}, \mathrm{G} .:$ GPS. Theory, algorithms and applications, Springer, Berlin, Germany, 2007.

Zinin, D. P., Teptin, G. M., and Khutorova, O. G.: Investigation of the effect of quasi-flat relief on the local inhomogeneous structure of the atmospheric boundary layer based on the modeling and the long-term experiment, Atmospheric and Oceanic Optics, 19, 487-490, 2006. 